\title{
Short exciton radiative lifetime in submonolayer InGaAs/GaAs quantum dots
}

\author{
Xu, Zhangcheng; Zhang, Yating; Tackeuchi, Atsuchi; Horikoshi, Yoshiji; Hvam, Jørn Märcher
}

\section{Published in:}

Applied Physics Letters

Link to article, DOI:

$10.1063 / 1.2839312$

Publication date:

2008

Document Version

Publisher's PDF, also known as Version of record

Link back to DTU Orbit

Citation (APA):

Xu, Z., Zhang, Y., Tackeuchi, A., Horikoshi, Y., \& Hvam, J. M. (2008). Short exciton radiative lifetime in submonolayer InGaAs/GaAs quantum dots. Applied Physics Letters, 92(6), 063103.

https://doi.org/10.1063/1.2839312

\section{General rights}

Copyright and moral rights for the publications made accessible in the public portal are retained by the authors and/or other copyright owners and it is a condition of accessing publications that users recognise and abide by the legal requirements associated with these rights.

- Users may download and print one copy of any publication from the public portal for the purpose of private study or research.

- You may not further distribute the material or use it for any profit-making activity or commercial gain

- You may freely distribute the URL identifying the publication in the public portal 


\title{
Short exciton radiative lifetime in submonolayer InGaAs/GaAs quantum dots
}

\author{
Zhangcheng $\mathrm{Xu}^{\mathrm{a})}$ and Yating Zhang \\ Nano-photonics Group, Key Laboratory of Weak-Light Nonlinear Photonics Materials (MOE), \\ TEDA College, Nankai University, Tianjin 300457, People's Republic of China \\ and National Laboratory for Infrared Physics, Chinese Academy of Sciences, Yutian Road No. 500, \\ Shanghai 200083, People's Republic of China \\ Atsushi Tackeuchi and Yoshiji Horikoshi \\ School of Science \& Engineering, Waseda University, Sinjuku-Ku, Tokyo 169-8555, Japan \\ Jørn M. Hvam \\ Department of Communications, Optics and Materials, and Nano. DTU, Technical University of Denmark, \\ DK-2800 Lyngby, Denmark
}

(Received 2 October 2007; accepted 10 January 2008; published online 12 February 2008)

\begin{abstract}
The exciton radiative lifetime in submonolayer (SML) InGaAs/GaAs quantum dots (QDs) grown at $500{ }^{\circ} \mathrm{C}$ was measured by using time-resolved photoluminescence from 10 to $260 \mathrm{~K}$. The radiative lifetime is around $90 \mathrm{ps}$ and is independent of temperature below $50 \mathrm{~K}$. The observed short radiative lifetime is a key reason for the high performance of SML QD devices and can be explained by the theory of Andreani et al. [Phys. Rev. B 60, 13276 (1999)] calculating the radiative lifetime of QDs formed at the interface fluctuations of a quantum well, as the SML QDs are 20-30 nm in diameter and embedded within the lateral InGaAs QW. (C) 2008 American Institute of Physics.
\end{abstract}

[DOI: $10.1063 / 1.2839312$ ]

The stacked submonolayer (SML) growth of quantum dots (QDs) presents an alternative approach to StranskiKrastanow (SK) grown QDs. ${ }^{1}$ SML quantum dots have been used to fabricate high-power edge-emitting lasers ${ }^{2-4}$ and single-mode vertical-cavity surface-emitting lasers (VCSELs) with high modulation bandwidth. ${ }^{5,6}$ Self-sustained pulsation in the oxide-confined VCSELs based on SML InGaAs QDs has recently been observed. ${ }^{7}$ The high performance of SML QD lasers has usually been ascribed to the high density and uniformity of SML QDs.

As a matter of fact, another important parameter determining the maximum modal gain $\left(g_{\bmod }\right)$ for transition in a QD is the exciton radiative lifetime $(\tau),{ }^{8}$ i.e., $g_{\bmod } \propto 1 / \tau$. In our previous work, ${ }^{9}$ we investigated the carrier dynamics of SML InGaAs QDs grown at $480{ }^{\circ} \mathrm{C}$. The exciton radiation lifetime at $10 \mathrm{~K}$ was found to be around $700 \mathrm{ps}$; however, the QD photoluminescence (PL) signal quenches at room temperature. ${ }^{10}$ The PL signal from the SML QD ground state can be observed even at room temperature if we increase the growth temperature of SML QDs to $500{ }^{\circ} \mathrm{C} .{ }^{11}$ Lasers using high-temperature grown (HTG) SML QDs show very high modal gain and zero linewidth enhancement factor. ${ }^{11}$ In this letter, we report the exciton radiative lifetime of HTG SML QDs from 10 to $260 \mathrm{~K}$, via time-resolved photoluminescence (TRPL). We found that the exciton radiative lifetime in SML QDs is around 90 ps and is almost independent of temperature below $50 \mathrm{~K}$.

The sample was grown on a semi-insulating GaAs $(00$ 1) substrate via molecular beam epitaxy. The layer structure of the sample is depicted in Fig. 1. The SML QD layer was formed with ten cycles of alternate deposition of $0.5 \mathrm{ML}$ InAs and 2.5 ML GaAs, at $500{ }^{\circ} \mathrm{C}$, the same as in Ref. 11 . The inset of Fig. 1 shows the in-plane transmission electron

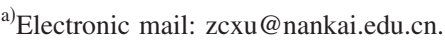

microscope (TEM) image of SML QDs. The characteristic size of the SML QDs is $20-30 \mathrm{~nm}$ in diameter, which lies between the reported value in Refs. 6 and 12 .

In the TRPL setup, the sample was cooled in a closedcycle He cryostat and excited in the GaAs barriers with $130 \mathrm{fs}$ pulses from a Ti:sapphire laser at the wavelength of $400 \mathrm{~nm}$. The PL signal was collected, dispersed, and synchronously detected using a streak camera with overall time resolution of $15 \mathrm{ps}$. The excitation spot in TRPL is about $100 \mu \mathrm{m}$ in diameter.

The time-integrated PL spectrum of the HTG SML QDs at from 10 to $260 \mathrm{~K}$ is shown in Fig. 2(a). At $10 \mathrm{~K}$, the PL band shows a peak at $1.355 \mathrm{eV}$ with a full width at the half maximum of $19 \mathrm{meV}$ and the wavelength-integrated PL in-

\begin{tabular}{|c|}
\hline  \\
\hline 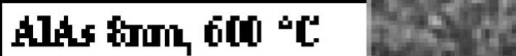 \\
\hline 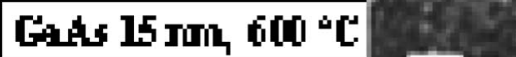 \\
\hline GALs 5 min $500^{\circ} \mathrm{C}$ \\
\hline GLGAs S ML, 500 $\triangle$ [, DDs \\
\hline 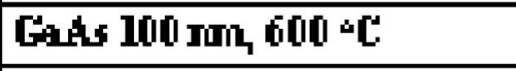 \\
\hline 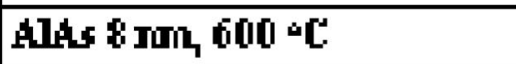 \\
\hline CHAs lall Jum, fillo ${ }^{\circ} \mathrm{C}$ \\
\hline 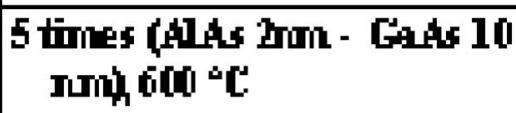 \\
\hline Cople Sulbitrate \\
\hline
\end{tabular}

FIG. 1. The layer structure of InGaAs SML QD sample. The inset shows the in-plane TEM image of SML QDs. 



FIG. 2. (Color online) (a) The time-integrated PL spectrum from SML InGaAs/GaAs QDs at different temperatures. (b) The energy shift of the PL peak with respect to the temperature. (c) The variation of the integrated PL intensity with respect to the temperature. The dots and the solid lines in (b) and (c) represent the experimental and the fitting results, respectively.

tensity increases linearly with the increase of the excitation power, indicating very low defect density in our sample. As shown in Fig. 2(b), the peak energies of the PL band redshifts as the temperature increases, and the trend can be well fitted by using Varshini formula, ${ }^{13} E(T)=E(0 \mathrm{~K})-\alpha T^{2} /(\beta$ $+T)$. Here, $E(T)$ is the peak energy at temperature $T$, $E(0 \mathrm{~K})=1.355 \mathrm{eV}, \alpha=3.56 \times 10^{-4} \mathrm{eV} / \mathrm{K}, \beta=83 \mathrm{~K}$. Figure 2(c) shows that the integrated PL intensity is kept constant below $50 \mathrm{~K}$ and then decreases as the temperature increases, with a thermal activation energy of $E_{a}=31 \mathrm{meV} . E_{a}$ is determined by fitting the experimental data with the formula $I(T)=I(10 \mathrm{~K}) /\left(1+A \exp \left(-E_{a} / k T\right)\right.$, where $I(T)$ is the integrated PL intensity at temperature $T, k$ is the Boltzmann constant, and $A$ is a fitting parameter.

In order to clarify the origin of the activation energy, we measured the surface photovoltaic (SPV) signal from the SML QD laser structure of Ref. 11. The experiments were carried out at room temperature, under the condition of normal incidence. As shown in Fig. 3, three peaks can be clearly identified. The peak located at $1.276 \mathrm{eV}$ is due to the QD ground states. The broad peak from 1.334 to $1.352 \mathrm{eV}$ is due to the lateral quantum well $(\mathrm{QW})$ states. $^{10,12}$ The third broad peak located at $1.43 \mathrm{eV}$ is ascribed to the doped GaAs barrier. Assuming the conduction (valence) bandoffset to be 60 $(40 \%)$ of the bandgap offset between the QDs and the lateral $\mathrm{QW}$, the conduction bandoffset will be $34.8 \mathrm{meV}$. This value is very close to the measured thermal activation energy of $31 \mathrm{meV}$, suggesting that the PL quenching at high temperature is mainly due to the thermal escape of carriers from the QDs to the lateral QWs.

Figure 4(a) shows the PL transients at different emission energies at $10 \mathrm{~K}$. The PL decay time $\tau_{d}$ can be obtained by fitting the curve with a single exponential process. Figure 4(b) shows $\tau_{d}$ across the PL band. It can be seen that $\tau_{d}$ at the

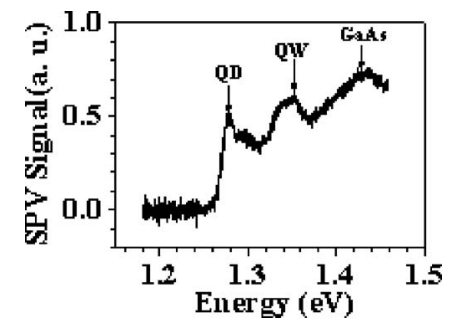

FIG. 3. The surface photovoltaic signal from a SML InGaAs/GaAs QD laser structure at room temperature. InGaAs/GaAs QDs.
Downloaded 21 Jun 2010 to 192.38.67.112. Redistribution subject to AIP license or copyr

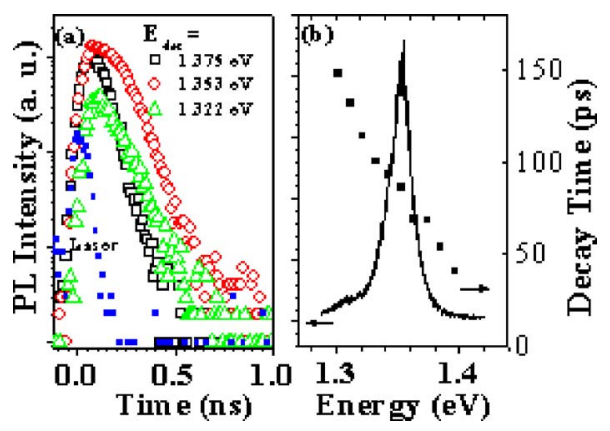

FIG. 4. (Color online) (a) The PL transients of HTG SML InGaAs QDs detected at different emission energies at $10 \mathrm{~K}$. (b) The PL decay time as a function of emission energies.

PL peak energy is as short as $90 \mathrm{ps.} \mathrm{The} \mathrm{trend} \mathrm{for} \mathrm{the} \mathrm{size}$ dependence of $\tau_{d}$ for HTG SML InGaAs QDs is the same with that for low-temperature grown SML QDs. ${ }^{9}$ Figure 5(a) shows the PL transient detected at PL peak energies at different temperatures. The corresponding $\tau_{d}$ from 10 to $260 \mathrm{~K}$ is plotted in the inset of Fig. 5(a). It can be seen that $\tau_{d}$ is almost independent of temperature.

Now let us discuss the PL decay time $\tau(\mathrm{K})$ for HTG SML QDs. Below $50 \mathrm{~K}$, the integrated PL intensity is nearly independent of the temperature, so the measured PL decay time is dominated by the exciton radiative lifetime. The nonradiative process plays an important role above $50 \mathrm{~K}$, as the emission efficiency decreases as the temperature increases. Using the relations $\tau_{\mathrm{rad}}(T)=\tau(T) \times I(10 \mathrm{~K}) / I(T)$ and $\tau_{\text {nrad }}(T)=\tau(T) \times I(10 \mathrm{~K}) /[I(10 \mathrm{~K})-I(T)]$ given in Ref. 14 , the radiative $\left(\tau_{\text {rad }}\right)$ and nonradiative $\left(\tau_{\text {nrad }}\right)$ lifetimes at different temperatures, can be evaluated, as shown in Fig. 5(b). It can be seen that the radiative lifetime is around $90 \mathrm{ps}$, nearly independent of temperature below $50 \mathrm{~K}$ and then increases up to $800 \mathrm{ps}$ at $260 \mathrm{~K}$. The nonradiative lifetime decreases with the increase of temperature due to the thermal escape of carriers from the QDs to the lateral QWs. The nonradiative lifetime decreases to $100 \mathrm{ps}$ at $260 \mathrm{~K}$, which is very close to the reported value for SK InGaAs/GaAs QDs. ${ }^{15}$

In 2000, Fiore et al. reported that the PL decay time for SK InAs/InGaAs QDs varies from $1.2 \mathrm{~ns}$ (at $50 \mathrm{~K}$ ) to $1.8 \mathrm{~ns}$ (at $300 \mathrm{~K}) .^{16}$ The decrease of the radiative efficiency from 5 to $300 \mathrm{~K}$ by a factor of 13 was attributed to either the long radiative lifetime of $18 \mathrm{~ns}$ or the existence of the nonradiative traps in the $\operatorname{In}(\mathrm{Ga})$ As matrix around the QDs. The ob-
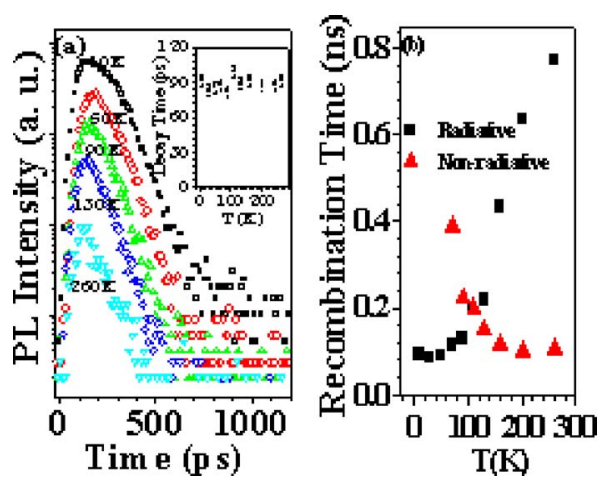

FIG. 5. (Color online) (a) The PL transient of HTG SML InGaAs QDs detected at the PL peak energies at different temperatures. (b) The temperature dependence of radiative lifetimes and nonradiative lifetimes of SML 
served long radiative lifetime for the SK QDs is normally attributed to the small overlap integral of the electron and hole wave functions due to the piezoelectric effect, ${ }^{8,17}$ and can be modified by thermal annealing. ${ }^{18}$ On the other hand, the low-temperature radiative lifetime of $\mathrm{InGaAs} / \mathrm{GaAs}$ quantum wells is around $400 \mathrm{ps},{ }^{19}$ much longer than the present case. Therefore, the observed short radiative lifetime for the HTG SML InGaAs QDs cannot be simply explained by the enhancement of the overlap integral of the electron and hole wave functions.

Very short radiative lifetime of $100 \mathrm{ps}$ for GaAs QDs formed at the interface fluctuation of a GaAs/AlGaAs QW has recently been observed by Hours et al. ${ }^{20}$ Actually, the SML InGaAs/GaAs quantum dots are disklike and embedded within the lateral quantum well, according to Refs. 10 and 12. They are very similar to the InGaAs QDs formed at the interface fluctuation of an InGaAs/GaAs QW. As predicted in the theory of Andreani et al., the oscillator strength should be very large and depends on the QD radius. ${ }^{21}$ Our previous results show that the radiative lifetime for SML InGaAs QDs of $7.5 \mathrm{~nm}$ in diameter is around $700 \mathrm{ps}$, due to the strong confinement. ${ }^{9}$ In the present work, the average lateral size of SML QDs is $25 \mathrm{~nm}$ and very close to the Bohr radius of excitons. ${ }^{22}$ According to the theory of Andreani et al., the carriers are confined within the SML QDs and the center of mass of the exciton is quantized with the lateral QW. The oscillator strength should be larger due to the larger area of the center of mass of the exciton wavefunction.

In summary, by using TRPL at various temperatures, we found that the exciton radiative lifetime of SML InGaAs QDs grown at high temperature is as short as $90 \mathrm{ps}$, and is almost independent of temperature below $50 \mathrm{~K}$. Above $50 \mathrm{~K}$, as the temperature increases, the radiative lifetime increases and reaches to $800 \mathrm{ps}$ at $260 \mathrm{~K}$. The observed short radiative lifetime can be explained using the theory of Andreani et al. calculating the radiative lifetime of the QDs formed at the interface fluctuations of a QW. The large oscillator strength of SML QDs is one of the key reasons for the high modal gain of the SML QD lasers and the high modulation bandwidth of SML QD VCSELs.

This work has been supported by the National Natural Science Foundation of China (Grant Nos. 60506013, 10774078, and 60444010), Program for New Century Excellent Talents in University (NCET-06-0213), the Danish Technical Science Research Council, the SRF for ROCS (SEM), the Startup fund for new employees of Nankai University, and the Marubun Research Promotion Foundation. The authors thank Mr. Fujita, Mr. Kusuno, Mr. Ushiyama, and Dr. S. L. Lu for their assistance in TRPL measurements and Dr.
Enomota for his assistance in TEM observations. The first author thanks Professor Zhanguo Wang, Professor Jingjun $\mathrm{Xu}$, Professor Wei Lu, and Professor Xiaoshuang Chen for their help.

${ }^{1}$ I. L. Krestnikov, N. N. Ledentsov1, A. Hoffmann, and D. Bimberg, Phys. Status Solidi A 183, 207 (2001).

${ }^{2}$ S. S. Mikhrin, A. E. Zhukov, A. R. Kovsh, N. A. Marleev, V. M. Ustinov, Y. M. Shernyakov, I. P. Soshnikov, D. A. Livshits, I. S. Tarasov, D. A. Bedarev, B. V. Volovik, M. V. Maximov, A. F. Tsatsulnikov, N. N. Ledenstov, P. S. Kopev, D. Bimberg, and Z. I. Alferov, Semicond. Sci. Technol. 15, 1061 (2000).

${ }^{3}$ A. F. Zhukov, A. R. Kovsh, S. S. Mikrin, N. A. Maleev, V. M. Ustinov, D. A. Livshits, I. S. Tarasov, D. A. Bedarev, M. V. Maximov, A. F. Tsatsulnikov, I. P. Soshnikov, P. S. Kopev, Z. I. Alferov, N. N. Ledentsov, and D. Bimberg, Electron. Lett. 35, 1845 (1999).

${ }^{4}$ A. R. Kovsh, A. E. Zhukov, N. A. Maleev, S. S. Mikhrin, D. A. Livshits, Y. M. Shernyakov, M. V. Maximov, N. A. Pihtin, I. S. Tarasov, V. M. Ustinov, Z. I. Alferov, J. S. Wang, L. Wei, G. Lin, J. Y. Chi, N. N. Ledentsov, and D. Bimberg, Microelectron. J. 34, 491 (2003).

${ }^{5}$ S. A. Blokhin, N. A. Maleev, A. G. Kuzmenkov, A. V. Sakharov, M. M. Kulagina, Y. M. Shernyakov, I. I. Novikov, M. V. Maximov, V. M. Ustinov, A. R. Kovsh, S. S. Mikhrin, N. N. Ledentsov, G. Lin, and J. Y. Chi, IEEE J. Quantum Electron. 42, 851 (2006).

${ }^{6}$ F. Hopfer, A. Mutig, M. Kuntz, G. Fiol, D. Bimberg, N. N. Ledentsov, V. A. Shchukin, S. S. Mikhrin, D. L. Livshits, I. L. Krestnikov, A. R. Kovsh, N. D. Zakharov, and P. Werner, Appl. Phys. Lett. 89, 141106 (2006).

${ }^{7}$ A. G. Kuzmenkov, V. M. Ustinov, G. S. Sokolovskii, N. A. Maleev, S. A. Blokhin, A. G. Deryagin, S. V. Chumak, A. S. Shulenkov, S. S. Mikhrin, A. R. Kovsh, A. D. McRobbie, W. Sibbett, M. A. Cataluna, and E. U. Rafailov, Appl. Phys. Lett. 91, 121106 (2007).

${ }^{8}$ L. V. Asryan, M. Grundmann, N. N. Ledentsov, O. Stier, R. A. Suris, and D. Bimberg, J. Appl. Phys. 90, 1666 (2001).

${ }^{9}$ Z. C. Xu, Y. T. Zhang, J. M. Hvam, J. J. Xu, X. S. Chen, and W. Lu, Appl. Phys. Lett. 89, 013113 (2006).

${ }^{10}$ Z. C. Xu, K. Leosson, D. Birkedal, V. Lyssenko, J. M. Hvam, and J. Sadowski, Nanotechnology 14, 1259 (2003).

${ }^{11}$ Z. C. Xu, D. Birkedal, M. Juhl, and J. M. Hvam, Appl. Phys. Lett. 85, 3259 (2004).

${ }^{12}$ Z. C. Xu, D. Birkedal, J. M. Hvam, Z. Y. Zhao, Y. M. Liu, K. T. Yang, A. Kanjilal, and J. Sadowski, Appl. Phys. Lett. 82, 3859 (2003).

${ }^{13}$ Y. P. Varshini, Physica (Amsterdam) 34, 149 (1967).

${ }^{14}$ G. Bacher, C. Hartmann, H. Schweizer, T. Held, G. Mahler, and H. Nickel, Phys. Rev. B 47, 9545 (1993).

${ }^{15}$ S. Marcinkevicius and R. Leon, Phys. Rev. B 59, 4630 (1999).

${ }^{16}$ A. Fiore, P. Borri, W. Langbein, J. M. Hvam, U. Oesterle, R. Houdré, R. P. Stanley, and M. Ilegems, Appl. Phys. Lett. 76, 3430 (2000).

${ }^{17}$ D. Bimberg, M. Grundmann, and N. N. Ledentsov, Quantum Dot Heterostructures (Wiley, New York, 1999).

${ }^{18}$ Z. C. Xu, Y. T. Zhang, and J. M. Hvam, Nanotechnology 18, 325401 (2007).

${ }^{19}$ G. Bacher, H. Scheizer, J. Kovac, A. Forchel, H. Nickel, W. Schlapp, and R. Losch, Phys. Rev. B 52, 1493 (1995).

${ }^{20}$ J. Hours, P. Senellart, E. Peter, A. Cavanna, and J. Bloch, Phys. Rev. B 71, 161306 (2005).

${ }^{21}$ L. C. Andreani, G. Panzarini, and J.-M. Gérard, Phys. Rev. B 60, 13276 (1999).

${ }^{22}$ H. Fu, L.-W. Wang, and A. Zunger, Phys. Rev. B 59, 5568 (1999). 